\title{
CONDROSARCOMA SINOVIAL: REPORTE DE UN CASO Y REVISION DE LA LITERATURA
}

\section{Dras. Sara Muñoz $\mathrm{Ch}^{(1)}$, Claudia Astudillo A $^{(2)}$.}

\section{Departamento Radiología, Clínica Las Condes \\ 2. Departamento de Imagenología, Hospital Clínico Universidad de Chile}

\begin{abstract}
A case of chondrosarcoma in a female patient is presented. This case was originated of synovial chondromatosis. The imaging and histological findings are discussed. We revised and comment previous reports.
\end{abstract}

Key words: Chondrosarcoma; Osteoarticular tumours, Synovial chondromatosis.

Resumen. Se presenta el caso de una paciente, del sexo femenino, con un condrosarcoma sinovial derivado de una transformación maligna de condromatosis sinovial. Se discuten los hallazgos en imágenes e histológicos. Se revisan y comentan los casos previamente publicados.

Palabras claves: Condromatosis sinovial, Condrosarcoma, Tumores ostearticulares.

\section{Introducción}

La Condromatosis sinovial es una artropatía relativamente poco común generalmente monoarticular, de causa desconocida, que se caracteriza por la presencia de islotes de tejido cartilaginoso, formados por metaplasia en el tejido conectivo subintimal de la sinovial y que pueden calcificar $u$ osificar.

Esta entidad es más frecuente en hombres y se presenta entre la tercera y séptima décadas de la vida. Puede comprometer grandes o pequeñas articulaciones como cadera, codo, tobillo, articulación temporo-mandibular, hombro, manos y pies. Sin embargo, la gran mayoría de los casos ocurren en la rodilla ${ }^{(2)}$. Clínicamente se puede presentar con dolor y aumento de volumen de la articulación.

Muñoz S. y cols. Condrosarcoma sinovial: Reporte de un caso y revisión de la literatura. Rev Chil Radiol 2004; 10: 24-27.

Correspondencia: Dra. Sara Muñoz Ch.

Depto de Radiología, Clínica Las Condes.

Lo Fontecilla 441, Las Condes. Santiago de Chile.

E-mail: sara.munoz@entelchile.net
La transformación maligna hacia condrosarcoma sinovial es muy infrecuente ${ }^{(1,3,5)}$. Sin embargo, existen algunos reportes en la literatura ${ }^{(1,3,6)}$, la mayoría de ellos en la articulación de la rodilla.

\section{Caso clínico}

Se presenta el caso de una mujer de 37 años con historia de gonalgia, desde los 18 años de edad, asociado a dolor y aumento de volumen progresivo en la rodilla derecha. Con la aparición de los primeros síntomas se practican radiografías simples, que demostraron cuerpos óseos irregulares intraarticulares, sin evidencias de compromiso óseo, del espacio articular, ni signos radiológicos de malignidad (Figura 1). Se operó y la biopsia dio como resultado condromatosis sinovial.

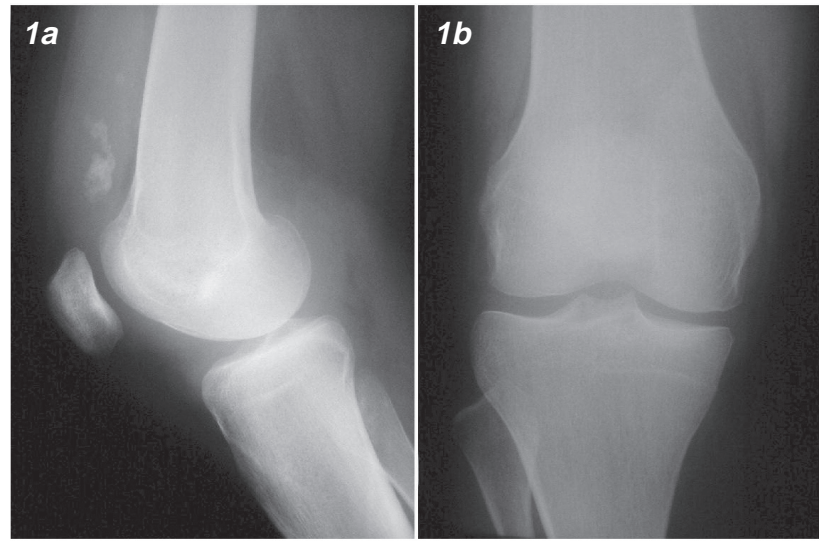

Figura 1 a,b. Radiografía de rodilla derecha inicial (Julio 1982) AP (a) y lateral (b) que demuestra aumento de volumen con densidad de partes blandas en región poplítea y receso suprarotuliano. Además se observa en este último la presencia de un cuerpo cálcico, característico de condromatosis sinovial.

Tres años más tarde presentó nuevamente aumento de volumen y dolor en la rodilla, siendo reintervenida y quedando con el mismo diagnóstico.

Evolucionó favorablemente durante los siguientes años, presentando en ocasiones derrame 
articular, que se manejó con punciones evacuadoras. Sin embargo, hubo un aumento de volumen de la rodilla, lentamente progresivo, agregándose compromiso funcional y dolor irradiado hacia la pierna, por lo cual volvió a consultar, constatándose en el examen físico al menos tres masas de ubicación suprarotuliana, infrarotuliana y hueco poplíteo (Figura 2). Esta última fue la de mayor volumen lo que determinó, en Febrero del año 2002, compromiso compresivo de la vena poplítea, lo que motiva su extirpación (Figura 3).

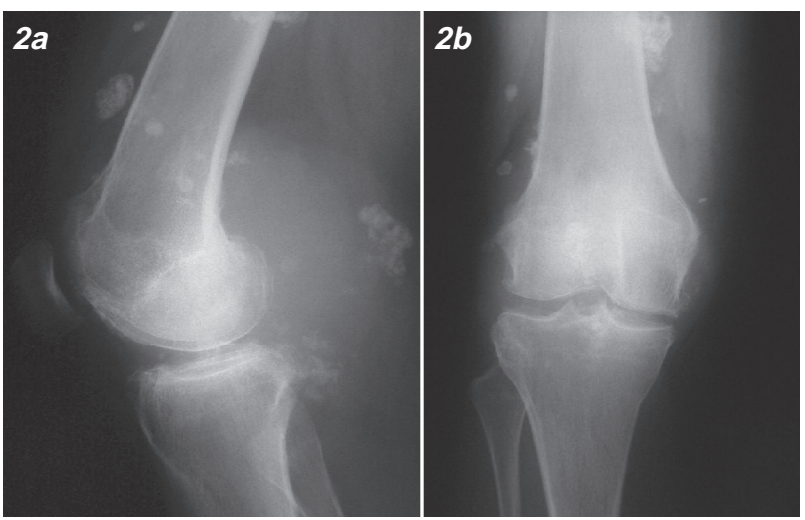

Figura 2 a,b. Radiografía de rodilla derecha AP (a) y lateral (b). Control de evolución 19 años después de primera intervención, se demuestra aumento de las lesiones y una gran masa poplítea. Existe además compromiso del espacio articular y osteofitos por la artropatía secundaria a la lesión sinovial.

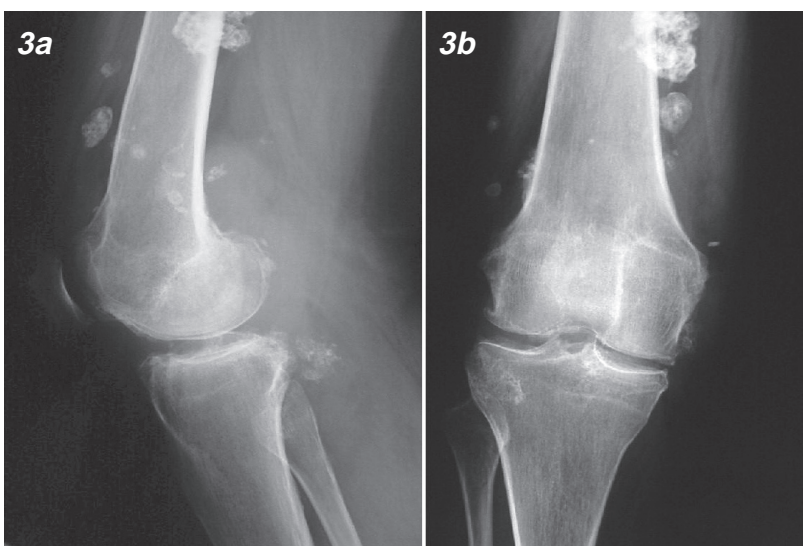

Figura 3 a,b. Control (Febrero 2002) después de cirugía en que se extirpó la gran masa que comprimía los vasos poplíteos. Radiografía de rodilla derecha AP (a) y lateral (b).

La muestra obtenida es enviada a anatomía patológica en dos centros diferentes, dando como resultado: Condrosarcoma sinovial tipo 1-2.

Tres meses después continuó con aumento de volumen progresivo, realizándose una resonancia magnética (RM) y un cintigrama óseo que muestra aumento irregular de actividad osteoblástica en rodilla derecha y partes blandas adyacentes, siendo el estudio de diseminación negativo (Figuras 4-8).
Por el diagnóstico histológico, las imágenes en RM y el progresivo compromiso funcional, se programa una nueva intervención paliativa para resecar la mayor cantidad de tumor. Posteriormente se decide mantenerla con tratamiento conservador.

\section{Discusión}

El condrosarcoma sinovial es una entidad infrecuente, que puede derivar de la transformación maligna de una condromatosis sinovial o bien aparecer de novo. No existen características imagenológicas específicas de malignidad ${ }^{(6)}$, y tanto la presentación clínica, como la radiológica pueden ser similares en condromatosis sinovial y condrosarcoma. La interpretación histológica es también difícil(7). El diagnóstico debe sospecharse clínicamente en casos crónicos con exacerbación repentina de la sintomatología, o en los casos que hay un importante aumento de volumen ${ }^{(4)}$.

Entre 1957 y 1997, se han reportado en la literatura $22 \operatorname{casos}^{(2)}$. En la mayoría de ellos, la lesión afectaba rodilla, cadera, tobillo y codo en orden decreciente. Este tumor afecta a pacientes en la cuarta a séptima década de la vida(2) y es más frecuente en hombres que en mujeres. La sintomatología clásica es aumento de volumen y dolor en la articulación afectada. En la mayoría de los casos el diagnóstico inicial es condromatosis sinovial y hay un intervalo de 1 mes a 24 años entre la escisión primaria y el diagnóstico final. Pueden presentar metástasis a distancia a los pulmones y raramente óseas ${ }^{(7)}$.

En condromatosis sinovial los hallazgos histológicos son variables ${ }^{(2)}$, pero en general el grado de celularidad es muy llamativo. Los condrocitos pueden ser prominentes, con núcleos grandes, con detalle nuclear interno visible. Pueden encontrarse núcleos dobles o múltiples en un mismo condrocito. Estos hallazgos pueden recordar al condrosarcoma óseo. Sin embargo, si la lesión se origina en los tejidos blandos o articulaciones, estos criterios que habitualmente indican malignidad, no son necesariamente aplicables ${ }^{(7)}$. A pesar de la celularidad de la condromatosis, los condrocitos tienen frecuentemente un patrón microscópico muy definido caracterizado por su ordenamiento en clones micronodulares.

En el condrosarcoma sinovial tiende a haber una pérdida de la micronodularidad y en general, se pierde el ordenamiento descrito para la condromatosis. La celularidad del condrosarcoma sinovial paradojalmente tiende a ser menor que en la condromatosis sinovial. Además, los condrocitos pueden tener apariencia mixoide y perder su apariencia lacunar, pudiendo presentar necrosis. La actividad mitótica es inusual. Tal vez el signo más importante para el diagnóstico diferencial entre 


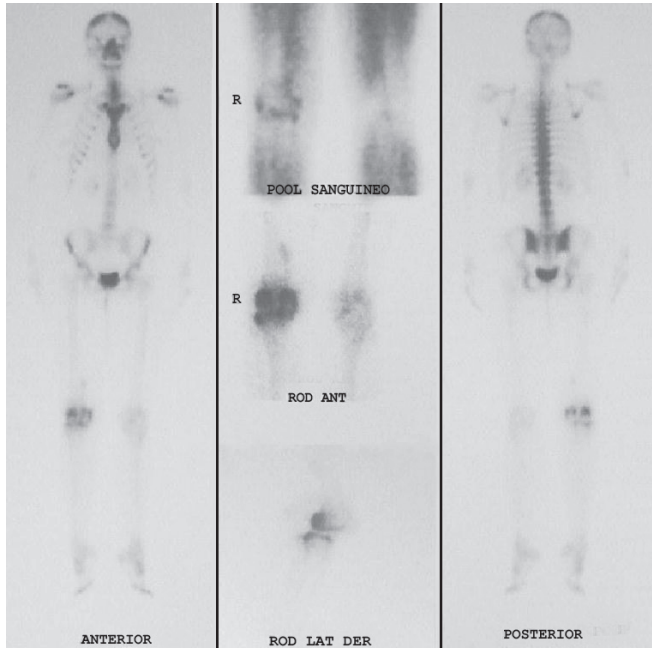

Figura 4. Cintigrama óseo (Mayo 2002) demostrando zonas hipercaptantes a nivel de rodilla derecha.

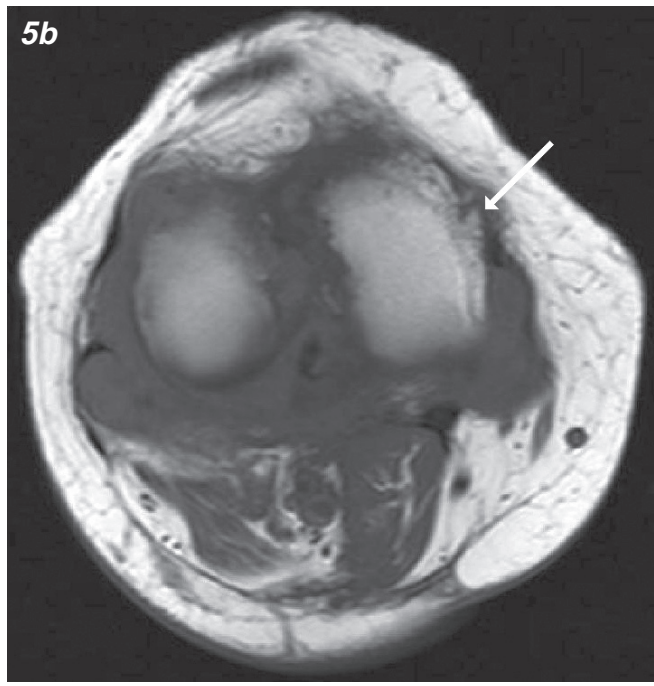

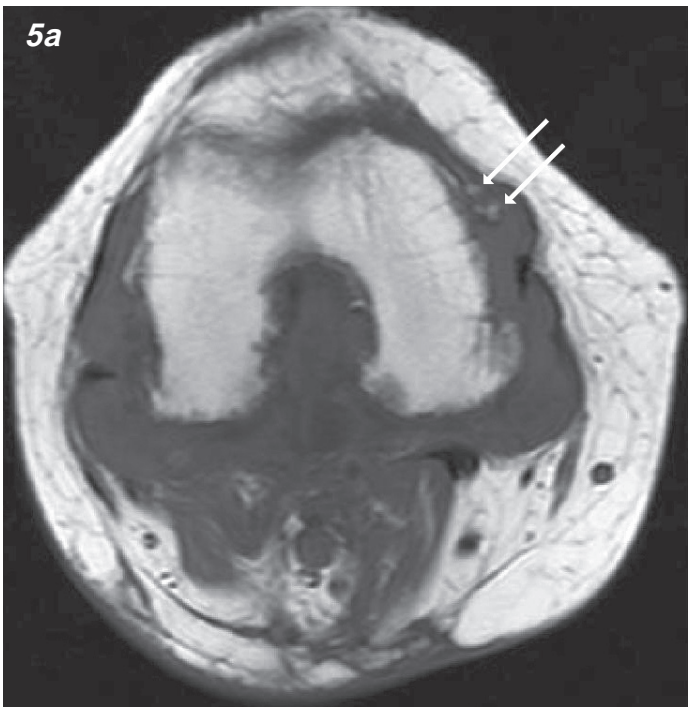

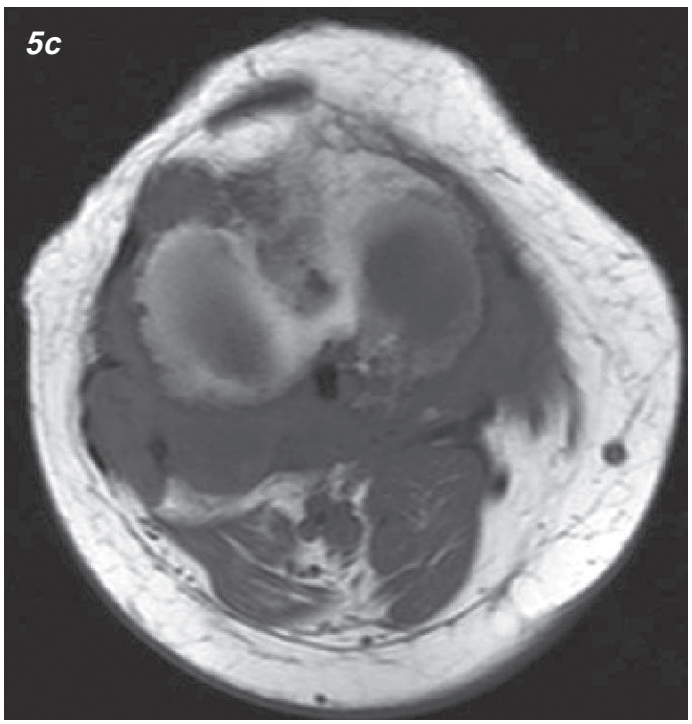

Figura 5 a-c. RM T1 axial (Mayo 2002). a: Se demuestra una extensa masa hipointensa homogénea ocupando los recesos sinoviales de la rodilla. Existe compromiso capsular, de los músculos y óseo cortical. Se obsevan además pequeños cuerpos óseos intraarticulares (flechas). b: Se aprecia en este corte la presencia de pequeños osteofitos (flecha). c: Compromiso óseo visible como irregularidad de la cortical.

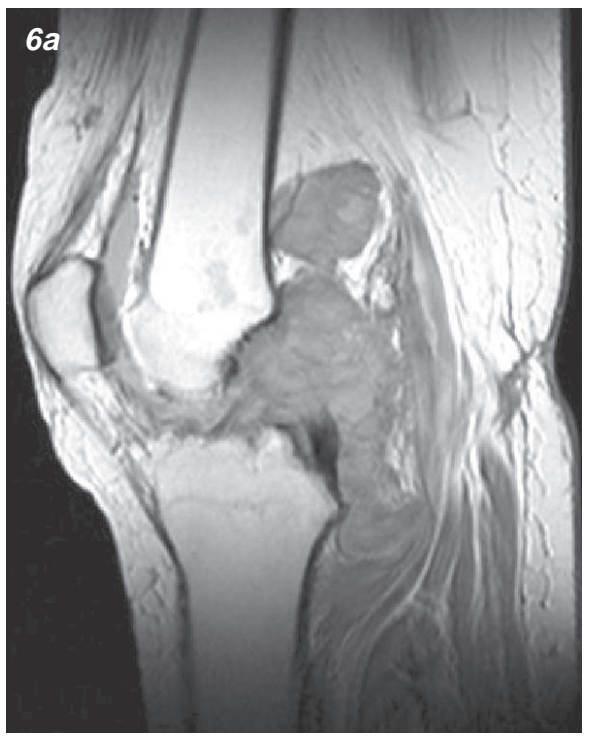

Figura 6 a,b. RM T1 sagital Densidad Protónica (Mayo 2002). En esta secuencia se observa la masa como una estructura de señal intermedia, destacando su extensión al hueco popliteo.

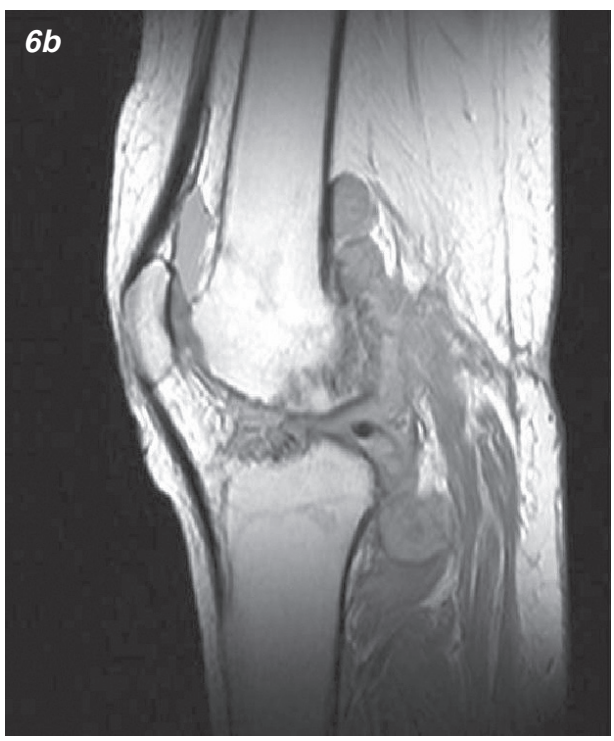



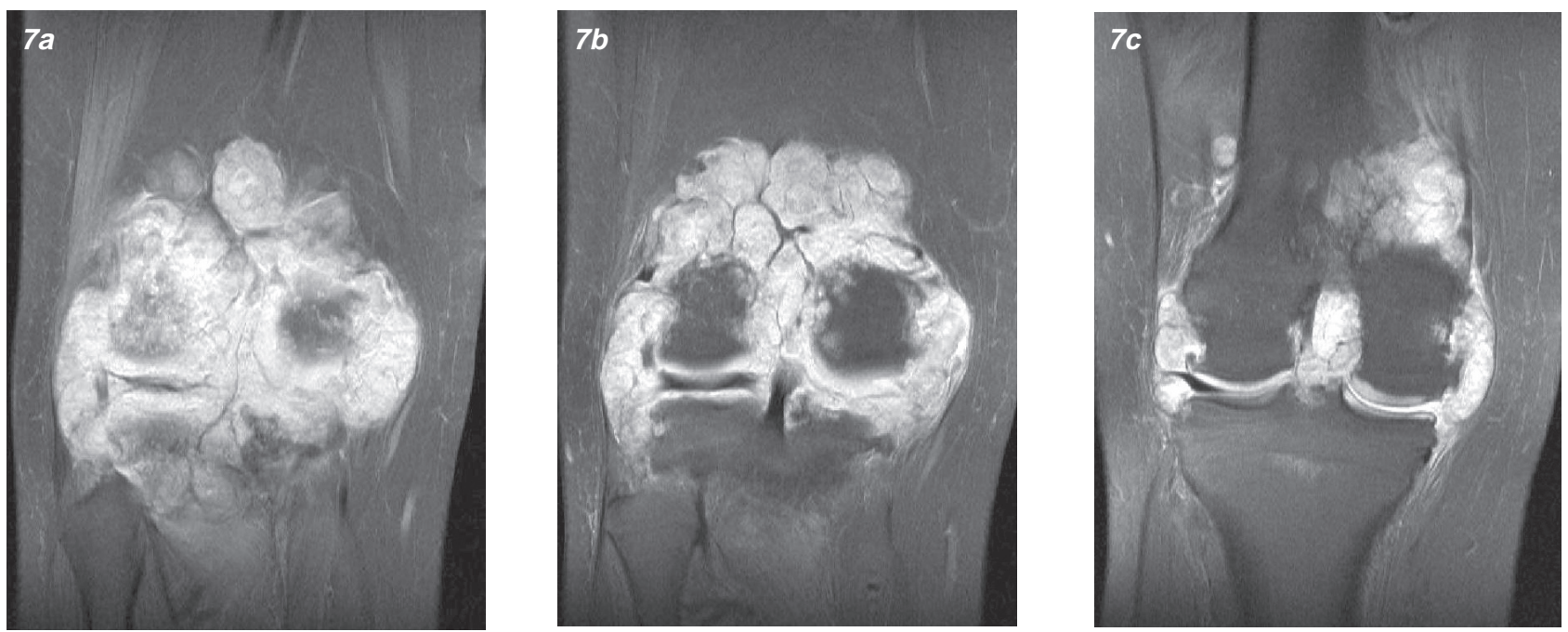

Figura 7 a-c. RM T2 con saturación grasa coronal. (Mayo 2002). La masa es visible hiperintensa y heterogenea, intra y extraarticular (a), sin compromiso del ligamento cruzado posterior (b) ni del anterior o meniscos (c).
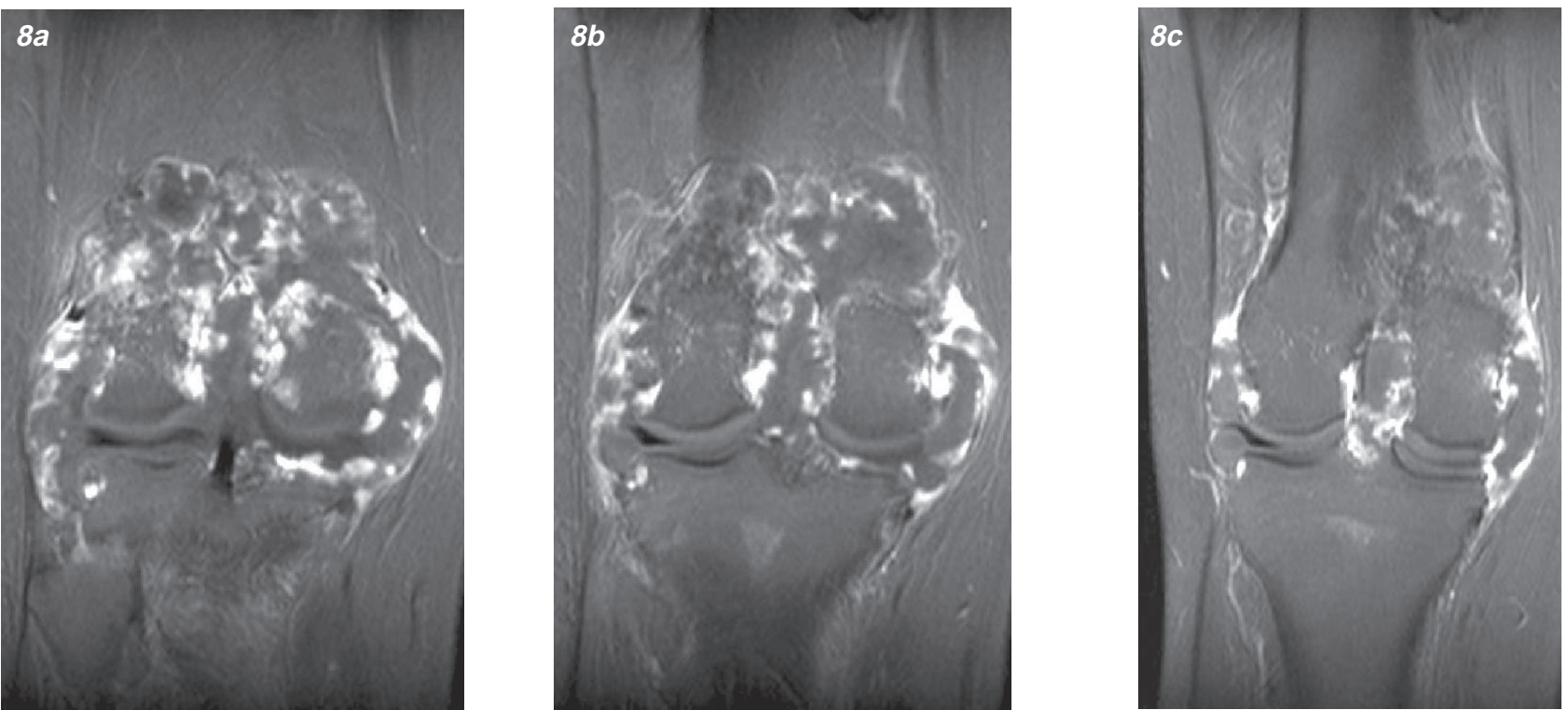

Figura 8 a-c. RM T1 con saturación de la grasa después de la inyección de Gadolinio (Mayo 2002). Se demuestra captación irregular como ocurre en tumores de origen cartilaginoso.

condromatosis sinovial y condrosarcoma sinovial, es la presencia de permeación ósea por el tejido cartilaginoso.

Nuestro caso se presentó en la articulación de la rodilla, que es la localización más frecuente y en una paciente del sexo femenino que es menos habitual. Hubo una larga evolución de la enfermedad antes del diagnóstico definitivo de condrosarcoma, al que se llegó luego de una tercera intervención quirúrgica y cuya indicación fue determinada por la compresión vascular provocada por el componente poplíteo de la masa.

\section{Bibliografía}

1. Taconis W, Van der Heul R, Tamimiau A. Synovial chondrosarcoma: report of a case and review of the literature. Skeletal Radiology 1997; 26: 682-685.

2. Hermann G, Klein M, Abdelwahab IF, Kenan S.
Synovial chondrosarcoma arising in synovial chondromatosis of the right hip. Skeletal Radiology 1997; 26: 366-369.

3. Wuisman P, Noorda R, Jutte P. Chondrosarcoma secondary to synovial chondromatosis. Report of two cases and a review of the literature. Arch Orthop Surg 1997; 116: 307-311.

4. Hallam P, Ashwood N, Cobb J. et al. Malignant transformation in synovial chondromatosis of knee? Knee 2001; 8: 239-242.

5. Ontell F, Greenspan A. Chondrosarcoma complicating synovial chondromatosis: finding with magnetic resonance imaging. Can Assoc Radiol J 1994; 45: 318-323.

6. Wittkop B, Davies A, Mangham D. Primary synovial chondromatosis and synovial chondrosarcoma: a pictorial review. Eur Radiol 2002; 12: 2112-9.

7. Kenan S, Abdelwahab IF, Klein M, Lewis M. Case report 817: Synovial chondrosarcoma secondary to synovial chondromatosis. Skeletal Radiology 1993; 22: 623-626. 